\title{
Long-term cost-effectiveness of atypical antipsychotics in the treatment of adults with schizophrenia in the US
}

This article was published in the following Dove Press journal:

ClinicoEconomics and Outcomes Research

12 September 2013

Number of times this article has been viewed

Ken O'Day'

Krithika Rajagopalan ${ }^{2}$

Kellie Meyer'

Andrei Pikalov ${ }^{2}$

Antony Loebel ${ }^{2}$

'Xcenda, Palm Harbor, FL,

${ }^{2}$ Sunovion Pharmaceuticals,

Marlborough, MA, USA
Correspondence: Ken O'Day Global Health Economics and Outcomes Research, Xcenda, 4I I 4 Woodlands Pkwy, Suite 500, Palm Harbor, FL 34685, USA

Tel + I 727 77| $4 \mid 56$

Fax +I 727 77| 4I44

Email ken.oday@xcenda.com
Background: The purpose of this study was to evaluate the long-term cost-effectiveness (including hospitalizations and cardiometabolic consequences) of atypical antipsychotics among adults with schizophrenia.

Methods: A 5-year Markov cohort cost-effectiveness model, from a US payer perspective, was developed to compare lurasidone, generic risperidone, generic olanzapine, generic ziprasidone, aripiprazole, and quetiapine extended-release. Health states included in the model were patients: on an initial atypical antipsychotic; switched to a second atypical antipsychotic; and on clozapine after failing a second atypical antipsychotic. Incremental cost-effectiveness ratios (ICERs) assessed incremental cost/hospitalization avoided. Effectiveness inputs included discontinuations, hospitalizations, weight change, and cholesterol change from comparative clinical trials for lurasidone and for aripiprazole, and the Clinical Antipsychotic Trials of Intervention Effectiveness for other comparators. Atypical antipsychotic-specific relative risk of diabetes obtained from a retrospective analysis was used to predict cardiometabolic events per Framingham body mass index risk equation. Mental health costs (relapsing versus nonrelapsing patients) and medical costs associated with cardiometabolic consequences (cardiovascular events and diabetes management) were obtained from published sources. Atypical antipsychotic costs were estimated from Red Book ${ }^{\circledR}$ prices at dose(s) reported in clinical data sources used in the model (weighted average dose of lurasidone and average dose for all other comparators). Costs and outcomes were discounted at 3\%, and model robustness was tested using one-way and probabilistic sensitivity analyses.

Results: Ziprasidone, olanzapine, quetiapine extended-release, and aripiprazole were dominated by other comparators and removed from the comparative analysis. ICER for lurasidone versus risperidone was $\$ 25,884 /$ relapse-related hospitalization avoided. At a $\$ 50,000$ willingness-topay threshold, lurasidone has an $86.5 \%$ probability of being cost-effective, followed by a $7.2 \%$ probability for olanzapine, and $6.3 \%$ for risperidone. One-way sensitivity analysis showed the model is sensitive to lurasidone and generic risperidone hospitalization rates.

Conclusion: Generic risperidone is the least costly atypical antipsychotic. Lurasidone is more costly and more effective than risperidone and is cost-effective at willingness-to-pay thresholds of greater than $\$ 25,844$ per hospitalization avoided. The favorable cost-effectiveness of lurasidone is driven by its clinical benefits (eg, efficacy in preventing hospitalizations in patients with schizophrenia) and its minimal cardiometabolic adverse effect profile.

Keywords: cost-effectiveness, economic, model, schizophrenia, atypical antipsychotic

\section{Introduction}

The diagnosed prevalence of schizophrenia in the US is only $0.51 \%,{ }^{1}$ yet the disease imposes a significant burden on patients, caregivers, and society, resulting in an 
estimated total annual excess cost of $\$ 62.7$ billion in 2002 in the US. ${ }^{2}$ Schizophrenia is also one of the most challenging diseases to treat due to its variable presentation, the heterogeneity of clinical response to treatment, poor adherence, and low rates of persistence with treatment. ${ }^{3,4}$

Poor adherence to antipsychotic treatment has been shown to increase the risk of relapse and subsequent hospitalization and to increase related resource utilization and costs. ${ }^{3,5,6}$ According to 2008 data from the Healthcare Cost and Utilization Project, there were 356,000 hospital stays for schizophrenia and other psychotic disorders in the US, comprising 19\% of all mental health and substance abuse-related hospitalizations. Patients admitted to hospital for schizophrenia have the highest average total cost per stay $(\$ 7,500)$, with an average duration of 11.1 days. $^{7}$ Patients who had experienced a relapse of psychotic symptoms within the previous 6 months incurred four times higher costs than schizophrenia patients without a recent relapse $(P<0.01)^{8}$

While atypical antipsychotics (AAPs) are relatively well tolerated, they are often associated with metabolic side effects. These adverse effects may include weight gain, hyperglycemia, insulin resistance, and lipid abnormalities. The American Diabetes Association Consensus on Antipsychotic Drugs and Obesity and Diabetes recognizes that certain atypical antipsychotic agents are also associated with increased risk of developing metabolic syndrome, new-onset diabetes, and cardiovascular disease. ${ }^{9}$ It has been reported that patients taking AAPs have approximately two times the risk of metabolic syndrome and diabetes compared with the general population. ${ }^{10,11}$ In addition, patients on AAPs have been found to be $9 \%$ more likely to develop diabetes than those taking conventional antipsychotics. ${ }^{12,13}$ Metabolic side effects of atypical antipsychotics, especially weight gain, may contribute to premature treatment discontinuation and poor adherence, ${ }^{4,14}$ which can lead to symptom worsening, relapse, and greater health care resource utilization. ${ }^{15,16}$

There has been continuing unmet clinical and economic need for new AAPs that not only effectively reduce the occurrence of acute relapses but also have a neutral or minimal impact on metabolic parameters. Such agents may have the potential to reduce the costs of care by reducing the incidence of new-onset diabetes or cardiovascular disease and/or improving treatment compliance and reducing acute exacerbations and subsequent hospitalizations. In clinical studies, lurasidone (Latuda ${ }^{\circledR}$, Sunovion Pharmaceuticals, Marlborough, MA, USA), an AAP approved by the US Food and Drug Administration in October 2010, has demonstrated lower annual rates of relapses and relapse-related hospitalizations compared with quetiapine extended-release. In addition, lurasidone also has been reported to have a more favorable cardiometabolic profile compared with other major AAPs in both clinical trials and in the real-world practice setting, thus potentially offering a cost-effective alternative therapy for patients with schizophrenia. ${ }^{17}$ Therefore, the objective of this health economic model was to assess the cost-effectiveness of lurasidone compared with other available generic and branded atypical antipsychotics in the treatment of schizophrenia from a US payer perspective, including direct medical costs; direct nonmedical costs and indirect costs, such as lost productivity, were not included in the model.

\section{Materials and methods Model design}

A Microsoft Excel ${ }^{\circledR}$-based Markov cohort model was developed to assess the cost-effectiveness of lurasidone compared with other AAPs available for treating adult patients with schizophrenia. Treatment comparators evaluated in the model included aripiprazole (Abilify ${ }^{\circledR}$, Bristol-Myers Squibb Company, Princeton, NJ, USA), lurasidone, olanzapine (generic), quetiapine extended-release (Seroquel $\mathrm{XR}^{\circledR}$, AstraZeneca Pharmaceuticals LP, Wilmington, DE, USA), risperidone (generic), and ziprasidone (generic). The costeffectiveness analysis was conducted over a 5-year time horizon from a third-party payer perspective in the US.

Costs and outcomes associated with AAPs and incorporating treatment switching were modeled using this Markov cohort analysis. Patients in the model start on lurasidone or another AAP (aripiprazole, olanzapine, quetiapine extended-release, risperidone, and ziprasidone). When patients discontinue the first AAP for any cause (adverse event or lack of efficacy), they transition to a "composite" AAP. The composite AAP therapy was incorporated into the model to account for treatment switching within a single state, as patients remain on the composite therapy until they fail due to lack of efficacy and transition to clozapine. ${ }^{18}$ Patients failing the composite due to adverse events were assumed to remain on the composite and continue to incur the associated costs and outcomes, thereby simulating treatment switching (Figure 1). The composite therapy was operationalized by averaging the discontinuation rates (transition probabilities), costs, and outcomes of the other comparator AAPs among which the patient might possibly switch (eg, if a patient initiates treatment with lurasidone, then the composite would reflect the average of aripiprazole, olanzapine, quetiapine extended-release, risperidone, and ziprasidone). 


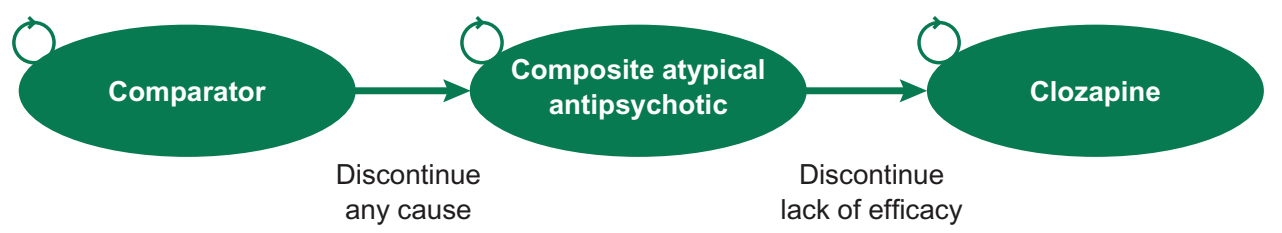

Figure I Cost-effectiveness model structure.

Patients discontinuing the composite health state due to lack of efficacy were considered to be refractory and were switched to clozapine. Patients switched to clozapine were projected to remain on clozapine for the remainder of the 5-year analysis.

Modeled costs in the analysis include pharmacy, mental health, diabetes management, and cardiovascular eventrelated costs inflated to 2012 US dollars using the Medical Care Component of the Bureau of Labor Statistics' Consumer Price Index. ${ }^{19}$ The model outcome was relapse-related hospitalizations avoided, and the per patient mean value was estimated over the 5-year time horizon. Costs in the model include the cost of hospitalizations; hence, to avoid doublecounting, the outcome represents the clinical benefit to patients associated with avoiding relapse and a subsequent hospitalization, and not cost savings. ${ }^{20} \mathrm{~A}$ standard discount rate of $3 \%$ was used for both costs and outcomes. The model comparators were ranked from least to most costly and then incremental cost-effectiveness ratios (ICERs), representing the difference in cost divided by the difference in outcome between the comparator agents, were calculated after excluding dominated and extendedly dominated options. One-way and probabilistic sensitivity analyses were also conducted to test model robustness.

\section{Model inputs}

\section{Patient characteristics}

The population for the model included adult patients diagnosed with schizophrenia. Patient characteristics for the base case scenario were specified to reflect the average schizophrenia patient enrolled in the lurasidone clinical trials: male ( $73 \%$ of patients were male), age 38 years, weight $77.3 \mathrm{~kg}$, body mass index (BMI) 26.3, with a mean total cholesterol of $192 \mathrm{mg} / \mathrm{dL}$, high-density lipoprotein of $48 \mathrm{mg} / \mathrm{dL}$, and systolic blood pressure (BP) of $120 \mathrm{mmHg} .{ }^{21,22} \mathrm{In}$ addition, $5.5 \%$ of patients were assumed to have diabetes and $67 \%$ to be smokers. In the model, patient gender, high-density lipoprotein, systolic BP, and smoking were static and did not change over time. Patient age, total cholesterol, and diabetes were a function of time (age), therapy (diabetes), and time on therapy (total cholesterol). Patient characteristics were used to estimate the risk of cardiovascular events and mortality in the model based on Framingham risk equations. ${ }^{23}$

\section{Effectiveness parameters}

Effectiveness parameters were obtained from adjusted indirect comparisons of various outcome measures from different clinical sources. The annual transition probabilities between the different Markov states were based on rates for total discontinuation, discontinuation due to lack of efficacy (used to determine relapses), and hospitalizations (used to determine relapse-related hospitalizations) from four major data sources (Table 1).

Discontinuation due to lack of efficacy and hospitalization rates for olanzapine, risperidone, quetiapine, and ziprasidone were obtained directly from the first phase of

Table I Discontinuation and hospitalization rates

\begin{tabular}{|c|c|c|c|}
\hline Input & Base case & SE & Reference \\
\hline \multicolumn{4}{|l|}{ Lurasidone } \\
\hline Total discontinuation (\%) & 0.534 & $0.04 I$ & 24 \\
\hline Efficacy discontinuation (\%) & 0.143 & 0.044 & \\
\hline Hospitalization (\%) & 0.057 & 0.026 & \\
\hline \multicolumn{4}{|l|}{ Olanzapine } \\
\hline Total discontinuation (\%) & 0.491 & 0.025 & 4 \\
\hline Efficacy discontinuation (\%) & 0.099 & 0.014 & \\
\hline Hospitalization (\%) & 0.078 & 0.012 & \\
\hline \multicolumn{4}{|l|}{ Risperidone } \\
\hline Total discontinuation (\%) & 0.588 & 0.025 & 4 \\
\hline Efficacy discontinuation (\%) & 0.192 & 0.014 & \\
\hline Hospitalization (\%) & 0.105 & 0.014 & \\
\hline \multicolumn{4}{|l|}{ Quetiapine } \\
\hline Total discontinuation (\%) & 0.678 & 0.025 & 4 \\
\hline Efficacy discontinuation (\%) & 0.196 & 0.018 & \\
\hline Hospitalization (\%) & 0.140 & 0.016 & \\
\hline \multicolumn{4}{|l|}{ Ziprasidone } \\
\hline Total discontinuation (\%) & 0.649 & 0.034 & 4 \\
\hline Efficacy discontinuation (\%) & 0.168 & 0.023 & \\
\hline Hospitalization (\%) & 0.122 & 0.020 & \\
\hline \multicolumn{4}{|l|}{ Aripiprazole } \\
\hline Total discontinuation (\%) & 0.662 & 0.025 & 25 \\
\hline Efficacy discontinuation (\%) & 0.183 & 0.014 & \\
\hline Hospitalization (\%) & 0.144 & 0.012 & \\
\hline \multicolumn{4}{|l|}{ Clozapine } \\
\hline Total discontinuation (\%) & 0.379 & 0.061 & 27 \\
\hline Efficacy discontinuation (\%) & 0.069 & 0.030 & \\
\hline Hospitalization (\%) & 0.052 & 0.010 & \\
\hline
\end{tabular}

Abbreviation: SE, standard error. 
Clinical Antipsychotic Trials of Intervention Effectiveness (CATIE), a prospective double-blind study of 1,493 patients with schizophrenia. ${ }^{4}$ Given that the first phase of the CATIE trial was an 18-month study, the discontinuation rates over 18 months were adjusted to 12 months, assuming that the rate at which patients discontinued treatment was constant.

Discontinuation and hospitalization rates for aripiprazole and lurasidone were based on an indirect comparison with the drugs included in the CATIE trial. Aripiprazole was directly compared with olanzapine in a long-term, open-label study, ${ }^{25}$ in which the relative risk for all-cause discontinuation for aripiprazole was 1.349 , and the relative risk of discontinuation due to lack of efficacy was 1.851 . Therefore, the rates of total discontinuation and discontinuation due to lack of efficacy of olanzapine from the CATIE trial ${ }^{4}$ were multiplied by these relative risks to obtain estimates of the discontinuation rates for aripiprazole. Because no hospitalization rate was available for aripiprazole, estimation of this rate was based on the relative risk of lack of efficacy for aripiprazole in Chrzanowski et $\mathrm{al}^{25}$ and on the hospitalization rate for olanzapine from the CATIE trial. ${ }^{4}$

In a similar manner, lurasidone was indirectly compared with the other model comparators using a direct comparison with quetiapine extended-release in a double-blind, parallelgroup, 12-month comparative study. ${ }^{24}$ In that study, lurasidone was found to have a relative risk of discontinuation for any cause of 0.787 , a relative risk of discontinuation due to lack of efficacy of 0.728 , and a relative risk of hospitalization of 0.404 versus quetiapine extended-release. These respective rates for lurasidone were then multiplied by the rates of discontinuation for any cause, rates of discontinuation due to lack of efficacy, and rates of hospitalization for quetiapine immediate-release from the CATIE trial to derive the respective rates for lurasidone. Based on the results of randomized clinical trials comparing quetiapine extendedrelease $400 \mathrm{mg} /$ day and quetiapine immediate-release $400 \mathrm{mg} /$ day, it was assumed that quetiapine extended-release and quetiapine immediate-release have similar efficacy and safety profiles. ${ }^{26}$

Finally, the rates for clozapine were based on an 18-month study by McEvoy et $\mathrm{al}^{27}$ and were adjusted to 12 -month rates. Standard errors for the transition probabilities were calculated based on the proportions and sample sizes from the published studies.

\section{Cardiometabolic parameters}

The model structure also incorporates the costs and outcomes of cardiometabolic consequences of treatment with each AAP. Many AAPs have been associated with increased cardiovascular risk by causing weight gain, an increase in lipid levels, and a higher risk of diabetes. ${ }^{28}$ As such, cardiometabolic parameters in the model included annual weight change (kg/year), annual cholesterol change ( $\mathrm{mg} / \mathrm{dL} /$ year), and diabetes relative risk (Table 2).

The model incorporates these risk factors by utilizing data from comparative clinical trials ${ }^{4,24,25}$ of the rate of weight gain and lipid increase of AAPs and data from a large retrospective analysis of the risk of diabetes. ${ }^{29}$ In order to track time on therapy to estimate the amount of weight gain and lipid increase, time-dependent substates (tunnel states) based on the time at which a segment of the cohort initiates a new therapy, were incorporated into the cohort analysis. ${ }^{18}$ For each annual cycle in the model, the age of the patient cohort increases, baseline weight is adjusted by time on AAP therapy, total cholesterol is adjusted by time on AAP therapy, and diabetes is adjusted by the relative risk based on the AAP. These adjusted risk factors were then applied to the Framingham 10-year cardiovascular risk profile using the Framingham BMI risk equation. ${ }^{23}$

Table 2 Cardiometabolic parameters

\begin{tabular}{|c|c|c|c|}
\hline Input & $\begin{array}{l}\text { Base } \\
\text { case }\end{array}$ & SE & Reference \\
\hline Lurasidone, weight change (kg/year) & 0.70 & 1.64 & 24 \\
\hline $\begin{array}{l}\text { Lurasidone, cholesterol change } \\
\text { (mg/dL/year) }\end{array}$ & 0.0 & 1.6 & \\
\hline Lurasidone, diabetes relative risk & 1.00 & 0.04 & Assumption \\
\hline Olanzapine, weight change (kg/year) & 10.91 & 1.64 & 4 \\
\hline $\begin{array}{l}\text { Olanzapine, cholesterol change } \\
\text { (mg/dL/year) }\end{array}$ & 6.3 & 1.6 & \\
\hline Olanzapine, diabetes relative risk & 1.15 & 0.04 & 29 \\
\hline Risperidone, weight change (kg/year) & 2.18 & 1.64 & 4 \\
\hline $\begin{array}{l}\text { Risperidone, cholesterol change } \\
\text { (mg/dL/year) }\end{array}$ & -0.9 & 1.6 & \\
\hline Risperidone, diabetes relative risk & I.0I & 0.04 & 29 \\
\hline Quetiapine, weight change (kg/year) & 2.73 & 1.09 & 4 \\
\hline $\begin{array}{l}\text { Quetiapine, cholesterol change } \\
\text { (mg/dL/year) }\end{array}$ & 4.4 & 1.6 & \\
\hline Quetiapine, diabetes relative risk & 1.20 & 0.11 & 29 \\
\hline Ziprasidone, weight change (kg/year) & -1.64 & 1.64 & 4 \\
\hline $\begin{array}{l}\text { Ziprasidone, cholesterol change } \\
\text { (mg/dL/year) }\end{array}$ & -5.5 & 2.1 & \\
\hline Ziprasidone, diabetes relative risk & 1.00 & 0.04 & Assumption \\
\hline Aripiprazole, weight change (kg/year) & 2.06 & 1.64 & 25 \\
\hline $\begin{array}{l}\text { Aripiprazole, cholesterol change } \\
(\mathrm{mg} / \mathrm{dL} / \text { year) }\end{array}$ & -1.00 & 1.6 & \\
\hline Aripiprazole, diabetes relative risk & 1.00 & 0.04 & Assumption \\
\hline Clozapine, weight change (kg/year) & 2.73 & 2.73 & 27 \\
\hline $\begin{array}{l}\text { Clozapine, cholesterol change } \\
\text { (mg/dL/year) }\end{array}$ & 3.9 & 3.1 & \\
\hline Clozapine, diabetes relative risk & $\mathrm{I} .57$ & 0.15 & 29 \\
\hline
\end{tabular}

Abbreviation: SE, standard error. 
According to the BMI equation, cardiovascular risk is a function of age, BMI, untreated systolic BP, treated systolic BP, smoking, and diabetes. Finally, the 10-year risks were adjusted to one-year risks to calculate the expected number of annual cardiovascular disease events based on the cohort risk factors.

\section{Mortality rates}

Published age-specific and gender-specific mortality tables were used to determine patient mortality over the 5-year time horizon. ${ }^{30}$ The mortality risk due to cardiovascular events and suicide was estimated separately in the model; therefore, the population mortality rates were adjusted to exclude the increased mortality risks associated with suicide and cardiovascular disease among patients with schizophrenia. Patient suicides were calculated based on the rate per 100,000 patient-years (mean 579, standard error 52) from a published systematic review of suicide rates ${ }^{31}$ and were assumed to be identical for all AAPs. Cardiovascular disease mortality was estimated by multiplying the number of patients experiencing a cardiovascular event by the fatal cardiovascular event rate (mean 9.5\%, standard error $2.0 \%) .^{32}$

\section{Drug costs and resource utilization}

Annual drug costs were estimated based on the wholesale acquisition costs of each AAP (generic olanzapine, generic risperidone, generic ziprasidone, aripiprazole, quetiapine extended-release, and clozapine) as reported in the Red Book $^{\circledR}$ as of October 9, 2012 ${ }^{33}$ using the weighted average cost calculated based on the average daily dose from the CATIE trial (Table 3). Annual costs for lurasidone were based on patient utilization from a 12-month, multicenter, double-blind, parallel-group study of flexibly dosed lurasidone (40-160 mg/day), ${ }^{24}$ in which $15 \%$ of patients received a dose of $40 \mathrm{mg}$ or $80 \mathrm{mg}$ and $85 \%$ of patients received a dose of $120 \mathrm{mg}$ or $160 \mathrm{mg}$. Because lurasidone $160 \mathrm{mg}$ was not an approved dose and was as effective as the $120 \mathrm{mg}$ dose, for the purposes of the model, it was assumed that all patients receiving lurasidone $160 \mathrm{mg}$ received lurasidone $120 \mathrm{mg}$.

Resource utilization costs were obtained from the published literature (Table 3). The annual costs of psychiatric care were obtained from a published prospective, observational, noninterventional study of schizophrenia in the US comparing 310 patients with and 1,247 patients without a relapse. ${ }^{34}$ Relapse was defined as any of the following: psychiatric hospitalization, use of emergency services, use of a
Table 3 Annual treatment costs and resource utilization

\begin{tabular}{|c|c|c|c|}
\hline Input & Base case & SE & Reference \\
\hline \multicolumn{4}{|l|}{ Annual treatment costs } \\
\hline Lurasidone & $\$ 9,116$ & $\$ 456$ & 24,33 \\
\hline Olanzapine & $\$ 7,862$ & $\$ 393$ & 4,33 \\
\hline Risperidone & $\$ 2,239$ & $\$ 112$ & 4,33 \\
\hline Quetiapine & $\$ 9,853$ & $\$ 493$ & 4,33 \\
\hline Ziprasidone & $\$ 3,514$ & $\$ 176$ & 4,33 \\
\hline Aripiprazole & $\$ 9,748$ & $\$ 487$ & 25,33 \\
\hline Clozapine & $\$ 1,986$ & $\$ 99$ & 27,33 \\
\hline \multicolumn{4}{|l|}{ Resource utilization } \\
\hline No relapse cost & $\$ 11,535$ & $\$ 481$ & 34,19 \\
\hline $\begin{array}{l}\text { Relapse (no } \\
\text { hospitalization) cost }\end{array}$ & $\$ 13,358$ & $\$ 962$ & 34,19 \\
\hline $\begin{array}{l}\text { Relapse (with } \\
\text { hospitalization) cost }\end{array}$ & $\$ 44,223$ & $\$ 4,326$ & 34,19 \\
\hline Diabetes management & $\$ 7,900$ & $\$ 790$ & 35,19 \\
\hline $\begin{array}{l}\text { Cardiovascular } \\
\text { event cost }\end{array}$ & $\$ 40,637$ & $\$ 4,064$ & 32,19 \\
\hline
\end{tabular}

Note: All amounts shown in US dollars.

Abbreviation: SE, standard error.

crisis bed, or a suicide attempt, and was determined by systematic abstraction of data from patients' medical records. Drug costs were estimated using average wholesale price minus $15 \%$, and psychiatric hospitalizations were based on per diem costs adjusted across sites using their relative value units. Cost components included costs of medications (antipsychotics; other psychotropics, such as mood stabilizers, anticholinergics, antidepressants, antianxiety drugs; and sleep agents), psychiatric hospitalizations, day treatment, emergency services, psychosocial group therapy, medication management, individual therapy, and assertive community treatment/case management. Costs for patients with a relapse and a psychiatric hospitalization versus those with a relapse and no psychiatric hospitalization were differentiated by subtracting the hospitalization costs from the former group.

The costs of diabetes management were obtained from a study ${ }^{35}$ published by the American Diabetes Association that estimated the annual attributable costs of diabetes based on data from multiple sources, including the Medical Expenditure Panel Survey. This estimate included costs associated with hospital inpatient care, outpatient and physician office visits, emergency visits, nursing facility stays, home health visits, visits with other health professionals, and prescription drug and medical supply use. The rate of diabetes was multiplied by the annual diabetes cost to estimate the total costs of diabetes.

The annual costs of a cardiovascular event were estimated based on the one-month attributable costs from a 
large administrative claims analysis in the $\mathrm{US}^{32}$ using an incidence-based cost of illness that included costs for myocardial infarction, cardiac arrest, congestive heart failure, angina pectoris, transient ischemic attack, hemorrhagic stroke, ischemic stroke, peripheral vascular disease, coronary artery bypass graft surgery, and coronary angioplasty. The number of cardiovascular events was multiplied by the cost per event to estimate the total cost of cardiovascular disease events for the cohort.

\section{Sensitivity analyses}

The robustness of the model results were tested using a oneway deterministic sensitivity analysis and a probabilistic sensitivity analysis. The one-way deterministic sensitivity analysis was conducted to quantify the impact of uncertainty around the mean value of individual model parameters. For the low and high values, the one-way sensitivity analysis used the $95 \%$ confidence interval based on the mean and standard error for all model parameters.

In addition, sensitivity analyses using other scenarios listed below were conducted to evaluate the potential impact on the cost-effectiveness results:

- Using the Framingham lipid risk equation in place of the Framingham BMI risk equation

- Changing the discount rate from 3\% to a range of $0 \%-5 \%$

- Running the analysis with pharmacy costs only and removing cardiometabolic costs.

A probabilistic sensitivity analysis was conducted to quantify the impact of uncertainty of all model parameters by simultaneously sampling from the $95 \%$ confidence interval for each parameter distribution. Beta distributions were used for probabilities and percentages, log normal distributions were used for relative risks, and normal distributions were used for the remainder of parameters.

\section{Results}

Over the 5-year time horizon of the model, generic risperidone patients had the lowest total discounted health care costs, followed by generic ziprasidone, lurasidone, generic olanzapine, and other branded products, quetiapine extended-release and aripiprazole (Table 4). Lurasidone was associated with the lowest number of relapse-related hospitalizations $(0.40)$, followed by olanzapine $(0.42)$. Aripiprazole had the highest number of relapse-related hospitalizations (0.49). Full disaggregated model results are shown in Table 4.

In the incremental cost-effectiveness analysis, aripiprazole, quetiapine extended-release, and ziprasidone were dominated by risperidone (ie, more costly and less effective) whereas aripiprazole, quetiapine extended-release, and olanzapine were dominated by lurasidone and were therefore removed from the incremental analysis (Figure 2). The ICER for lurasidone versus risperidone was $\$ 25,884$ per relapserelated hospitalization avoided.

\section{Sensitivity analyses}

Figure 3 shows the results of the one-way sensitivity analysis comparing lurasidone and risperidone for the most impactful parameters at an assumed willingness-to-pay threshold of $\$ 50,000$ per hospitalization avoided. At this threshold, lurasidone is the preferred therapeutic option, with an incremental net monetary benefit of $\$ 1,480$ compared with risperidone. As shown in the tornado diagram, the model is sensitive to the following two parameters: lurasidone hospitalization rate (incremental net monetary benefit range, $-\$ 4,530$ to $\$ 7,489$ ) and risperidone hospitalization rate $(-\$ 1,469$ to $\$ 4,429)$. The model results were insensitive to the other model parameters over the tested ranges.

When costs of relapses and hospitalization are included and cardiometabolic costs are excluded from the analysis, the

Table 4 Discounted clinical outcomes and costs for atypical antipsychotics

\begin{tabular}{|c|c|c|c|c|c|c|}
\hline & Lurasidone & Olanzapine & Risperidone & Quetiapine XR & Ziprasidone & Aripiprazole \\
\hline \multicolumn{7}{|l|}{ Outcomes (per patient) } \\
\hline Hospitalizations & 0.3953 & 0.4182 & 0.4567 & 0.4857 & 0.4705 & 0.4907 \\
\hline Diabetes & 0.0591 & 0.0586 & 0.0591 & 0.0586 & 0.0598 & 0.0597 \\
\hline Cardiovascular disease events & 0.0373 & 0.0397 & 0.0376 & 0.0377 & 0.0372 & 0.0376 \\
\hline \multicolumn{7}{|l|}{ Costs (per patient) } \\
\hline Pharmacy & $\$ 29,947$ & $\$ 29,159$ & $\$ 25,519$ & $\$ 29,058$ & $\$ 26,483$ & $\$ 29,121$ \\
\hline Mental health & $\$ 71,142$ & $\$ 72,037$ & $\$ 73,960$ & $\$ 75,232$ & $\$ 74,513$ & $\$ 75,431$ \\
\hline Diabetes & $\$ 2,236$ & $\$ 2,289$ & $\$ 2,244$ & $\$ 2,292$ & $\$ 2,260$ & $\$ 2,260$ \\
\hline Cardiovascular & $\$ 1,5 \mid 4$ & $\$ 1,611$ & $\$ 1,528$ & $\$ 1,532$ & $\$ 1,5 \mid 2$ & $\$ 1,529$ \\
\hline Total costs & $\$ 104,840$ & $\$ 105,096$ & $\$ 103,251$ & $\$ 108,115$ & $\$ 104,768$ & $\$ 108,341$ \\
\hline
\end{tabular}

Note: All amounts shown in US dollars.

Abbreviation: $X R$, extended-release. 
Less effective and
more costly

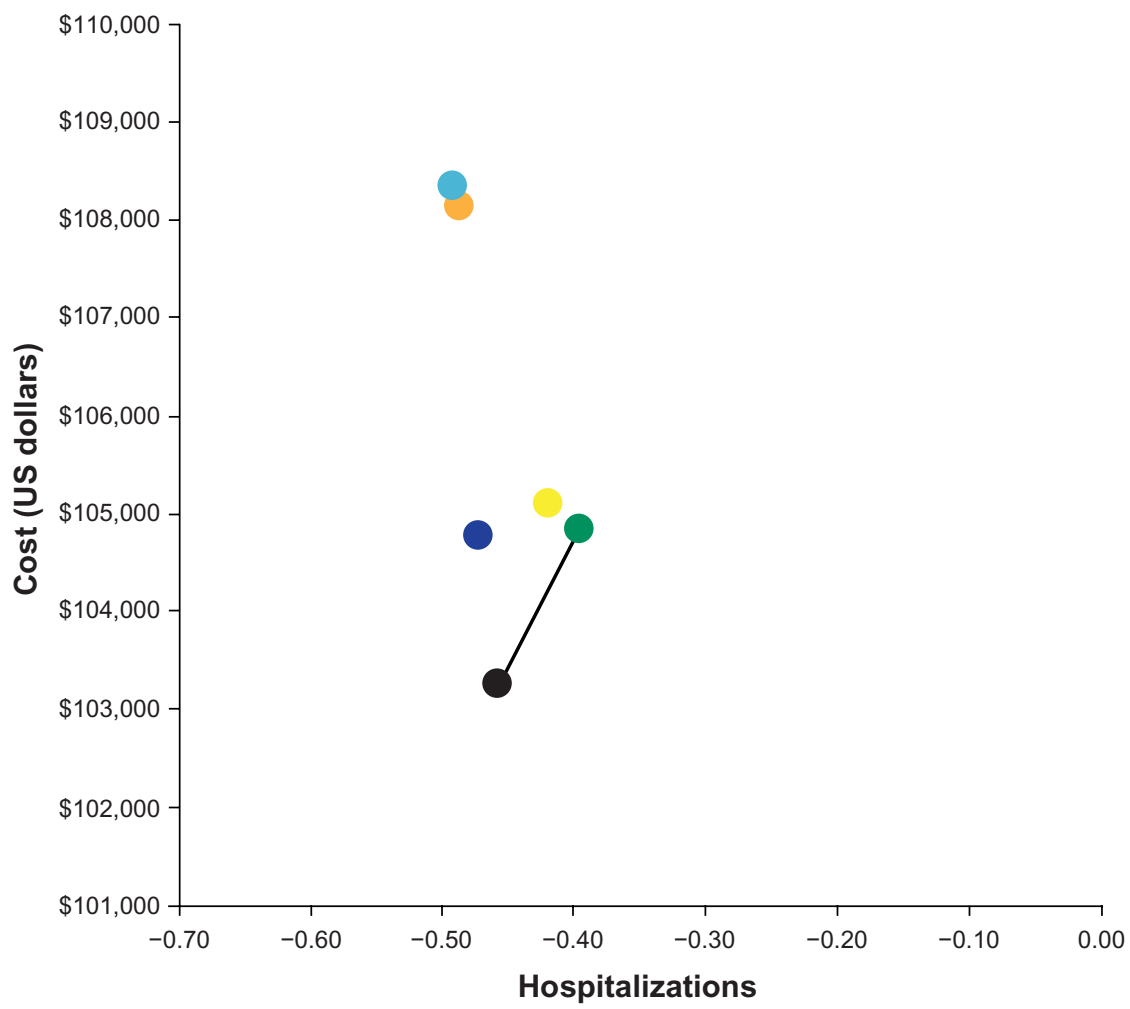

More effective and

more costly
Risperidone

Ziprasidone

- Lurasidone

Olanzapine

Q Quetiapine XR

Aripiprazole
Less effective and less costly
More effective and less costly

Figure 2 ICER per relapse-related hospitalization avoided.

Abbreviations: ICER, incremental cost-effectiveness ratio; $X R$, extended-release.

model results in an ICER of $\$ 26,109$ for lurasidone versus risperidone.

Results of the probabilistic sensitivity analysis at a willingness-to-pay threshold of $\$ 50,000$ per hospitalization avoided indicated that lurasidone is the most cost-effective AAP, followed by olanzapine, risperidone, ziprasidone, quetiapine extended-release, and aripiprazole (Table 5). At a willingness-to-pay threshold of $\$ 50,000$, lurasidone has an $86.5 \%$ probability of being cost-effective, followed by a $7.2 \%$ probability for olanzapine, and $6.3 \%$ for risperidone (Figure 4). At willingness-to-pay thresholds below approximately $\$ 26,000$ per relapse avoided,

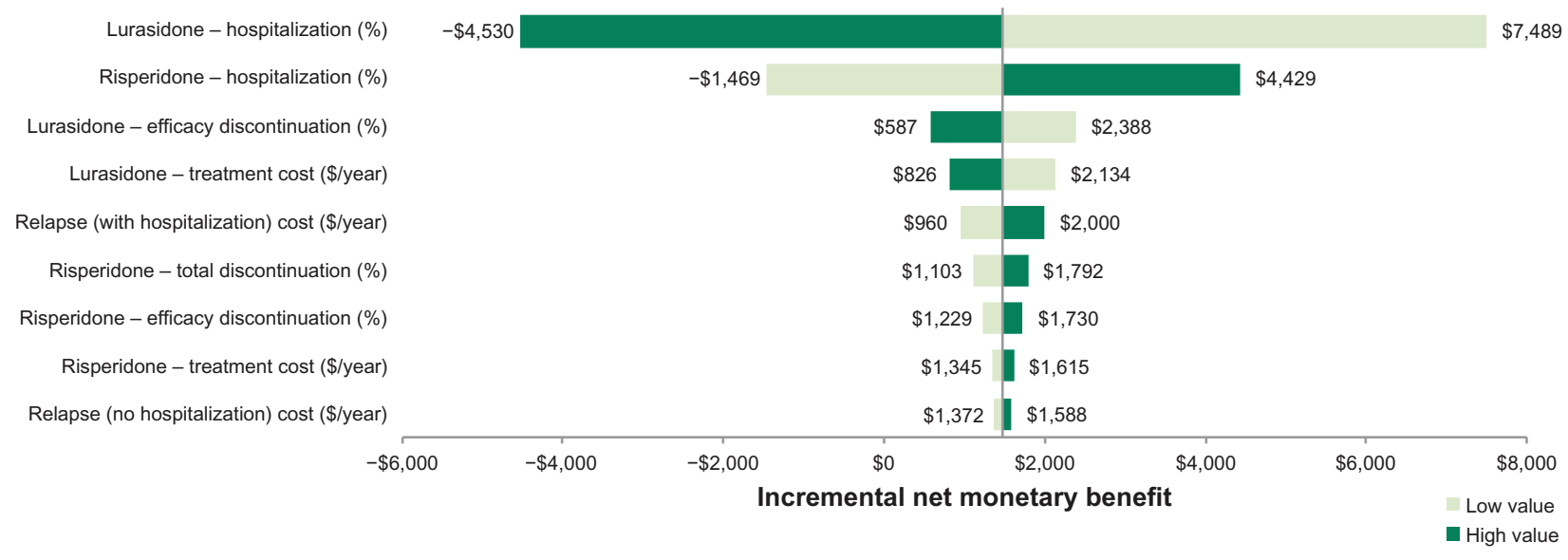

Figure 3 One-way sensitivity analysis results (tornado diagram). Note: Amounts shown are in US dollars. 
Table 5 Probabilistic sensitivity analysis results

\begin{tabular}{|c|c|c|c|c|}
\hline Rank & Drug & $\begin{array}{l}\text { Cost } \\
(95 \% \mathrm{Cl})\end{array}$ & $\begin{array}{l}\text { Hospitalizations } \\
(95 \% \mathrm{Cl})\end{array}$ & $\begin{array}{l}\text { Net monetary benefit } \\
(95 \% \mathrm{Cl})\end{array}$ \\
\hline I & Lurasidone & $\begin{array}{l}\$ 104,877 \\
(\$ 99,656, \$ 110,021)\end{array}$ & $\begin{array}{l}0.3955 \\
(0.3706,0.4225)\end{array}$ & $\begin{array}{l}-\$ 124,653 \\
(-\$ 130,282,-\$ 1 \mid 8,965)\end{array}$ \\
\hline 2 & Olanzapine & $\begin{array}{l}\$ 105,116 \\
(\$ 99,731, \$ 110,306)\end{array}$ & $\begin{array}{l}0.4183 \\
(0.4017,0.4368)\end{array}$ & $\begin{array}{l}-\$ 126,031 \\
(-\$ 13 \mid, 498,-\$ 120,405)\end{array}$ \\
\hline 3 & Risperidone & $\begin{array}{l}\$ 103,267 \\
(\$ 97,854, \$ 108,789)\end{array}$ & $\begin{array}{l}0.4568 \\
(0.4378,0.476 I)\end{array}$ & $\begin{array}{l}-\$ 126,107 \\
(-\$ 131,915,-\$ 120,352)\end{array}$ \\
\hline 4 & Ziprasidone & $\begin{array}{l}\$ 104,8 \mid 4 \\
(\$ 99,423, \$|10,47|)\end{array}$ & $\begin{array}{l}0.4712 \\
(0.4488,0.4959)\end{array}$ & $\begin{array}{l}-\$ 128,372 \\
(-\$ 134,243,-\$ 122,405)\end{array}$ \\
\hline 5 & Quetiapine XR & $\begin{array}{l}\$ 108,56 \\
(\$ 102,197, \$ 1|3,78|)\end{array}$ & $\begin{array}{l}0.4857 \\
(0.4662,0.5077)\end{array}$ & $\begin{array}{l}-\$ 132,442 \\
(-\$ 138,469,-\$ 126,166)\end{array}$ \\
\hline 6 & Aripiprazole & $\begin{array}{l}\$ 108,371 \\
(\$ 102,537, \$ 1 \mid 4,002)\end{array}$ & $\begin{array}{l}0.4908 \\
(0.4720,0.5114)\end{array}$ & $\begin{array}{l}-\$ 132,913 \\
(-\$ 138,886,-\$ 126,659)\end{array}$ \\
\hline
\end{tabular}

Note: a Net monetary benefit at a willingness-to-pay threshold of $\$ 50,000$ per hospitalization avoided. Amounts shown are in US dollars.

Abbreviations: $\mathrm{Cl}$, confidence interval; $\mathrm{XR}$, extended-release.

risperidone has the highest probability of being costeffective

\section{Discussion}

A similar study comparing lurasidone with aripiprazole for second-line use in patients with schizophrenia found lurasidone to be cost-effective. ${ }^{36}$ This is the first cost-effectiveness analysis comparing lurasidone with other AAPs for firstline use in patients with schizophrenia. The results of this cost-effectiveness analysis are generally comparable with the cost-effectiveness analyses of other AAPs that were recently published. A microsimulation model evaluating the cost-effectiveness of the AAPs olanzapine, risperidone, quetiapine, ziprasidone, and aripiprazole from a third-party payer perspective in the US over a one-year period showed that olanzapine had the lowest mean direct costs, followed by generic risperidone. Olanzapine was the dominant therapy for costs per quality-adjusted life-year (QALY). ${ }^{37}$ The total costs of adverse events, including extrapyramidal symptoms, weight gain, diabetes, and lipid abnormalities, were greatest for olanzapine, but the cost-effectiveness was driven by reduced inpatient hospitalizations. Another study comparing the cost-effectiveness of ziprasidone with that of olanzapine, risperidone, and quetiapine based on data from the CATIE trial from the Canadian health care perspective over a 5 -year period found that ziprasidone was less costly and more effective than olanzapine and quetiapine, ${ }^{38}$ however, the model included olanzapine at branded price. Similar to the results of this analysis, the model by McIntyre et a ${ }^{38}$ found that olanzapine had the highest costs related to cardiovascular and type 2

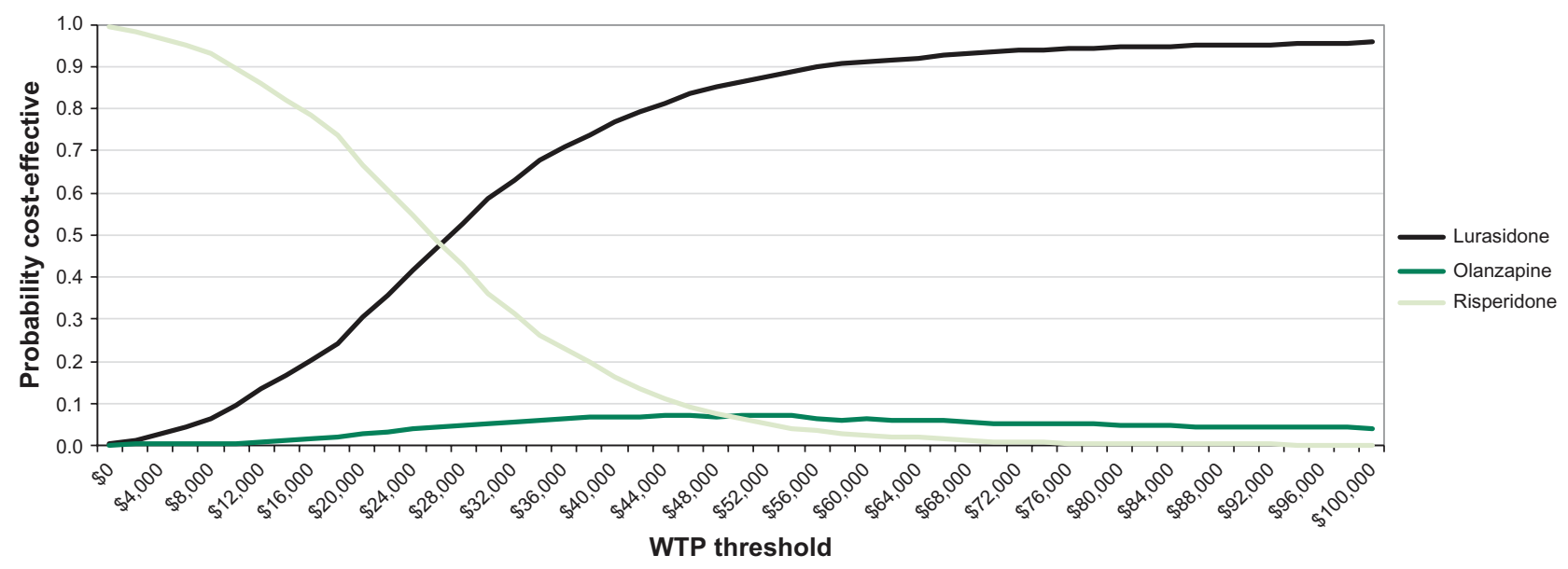

Figure 4 Cost-effectiveness acceptability curve.*

Note: *Ziprasidone, quetiapine XR, and aripiprazole all had $0 \%$ probability of being cost-effective across the tested range of WTP thresholds. Amounts shown are in US dollars. Abbreviations: WTP, willingness to pay; XR, extended-release. 
diabetes. Two other cost-effectiveness analyses comparing olanzapine and aripiprazole $\mathrm{e}^{39}$ and risperidone and olanzapine $\mathrm{e}^{40}$ yielded disparate results: the analysis by Ascher-Svanum et al, ${ }^{39}$ based on patient-level data from a randomized controlled trial, showed that olanzapine dominated risperidone. The analysis by Cooper et al, ${ }^{40}$ based on real-world insurance claims data in Canada, showed that use of risperidone was more cost-effective than olanzapine. These cost-effectiveness analyses, however, did not evaluate lurasidone as it was not available on the US market until early 2011.

The current therapeutic standard of care to manage symptoms and prevent clinical relapses associated with schizophrenia are AAPs, ${ }^{41,42}$ which are generally perceived to have an improved side effect profile over typical antipsychotics. ${ }^{43}$ However, prior to approval of lurasidone, results from two large non-industry-sponsored studies (CATIE and CUtLASS [Cost Utility of the Latest Antipsychotics in Schizophrenia Study]) demonstrated that some of the atypical agents, particularly clozapine and olanzapine, may be associated with metabolic side effects, including serious weight gain, diabetes, and hyperlipidemia. ${ }^{4,44,45}$ In a review article published in 2006, among the agents that were available on the market, the relative tendency to cause weight gain was as follows: clozapine $>$ olanzapine $>$ risperidone $=$ quetiapine $>$ ziprasidone $=$ aripiprazole. ${ }^{46}$ Clozapine and olanzapine are also associated with an increased risk of diabetes and dyslipidemia. ${ }^{45,47}$ Based upon a recent review of labels for all AAPs, including lurasidone, the relative tendency to cause weight gain is hypothesized to be as follows: olanzapine $=$ quetiapine $>$ risperidone $=$ iloperidone $>$ ziprasidone $>$ aripiprazole $>$ quetiapine extended-release $>$ paliperidone $=$ asenapine $>$ lurasidone..$^{48}$

A recent literature review of lurasidone clinical trials concluded that lurasidone has a minimal impact on body weight, with no clinically relevant associated changes observed in blood glucose, cholesterol, triglycerides, or the electrocardiographic QT interval. ${ }^{17}$ In clinical trials, glucose, lipid parameters, and weight with lurasidone were generally similar to placebo. Pooled data from short-term, placebo-controlled studies comparing lurasidone $40 \mathrm{mg}$, $80 \mathrm{mg}, 120 \mathrm{mg}$, and $160 \mathrm{mg}$ with placebo found a mean change from baseline in serum glucose of 2.6, $-0.4,2.5,2.5$, and $0.0 \mathrm{mg} / \mathrm{dL}$, respectively; mean change from baseline in total cholesterol of $-5.7,-6.2,-3.8,-6.9$, and $-5.8 \mathrm{mg} / \mathrm{dL}$, respectively; mean change from baseline in triglycerides of $-5.1,-13.0,-3.1,-10.6$, and $-13.4 \mathrm{mg} / \mathrm{dL}$, respectively; and mean change from baseline weight of $0.22,0.54,0.68,0.60$, and $-0.02 \mathrm{~kg}$, respectively. ${ }^{49}$ Because of the more favorable cardiometabolic profile with lurasidone, the impact of cardiovascular and metabolic-related side effects may be lower, resulting in lower costs for payers.

The present economic analysis was conducted to estimate the costs and outcomes associated with initial treatment with lurasidone compared with other AAPs in the treatment of schizophrenia. To allow comprehensive evaluation of the costs and outcomes, the potential cardiometabolic adverse events and increased health care costs associated with AAP treatments were also included. The base case results from the cost-effectiveness model found generic risperidone and generic ziprasidone to be the least costly treatments, with varying effects on hospitalization avoidance, as expected. However, lurasidone was found to have the lowest total costs among the branded agents, with best effects on hospitalization avoidance. Lurasidone dominated (was less costly and more effective) olanzapine, quetiapine extended-release, and aripiprazole in terms of relapse-related hospitalizations. Lurasidone was more costly and more effective than generic risperidone, with an ICER of $\$ 25,884$.

\section{Limitations}

The validity of any cost-effectiveness analysis is only as plausible as the inputs and assumptions made within the model. While the authors have attempted to ensure that the model's assumptions are valid, there are some limitations with the model that need to be recognized. First, the cost-effectiveness model does not account for patient heterogeneity, which is a limitation of all Markov cohort models. In the base case, patients were assumed to reflect the average schizophrenia patient enrolled in the lurasidone clinical trials, ${ }^{21,22} \mathrm{ie}$, male, aged 38 years, weight $77.3 \mathrm{~kg}$, BMI 26.3, total cholesterol $192 \mathrm{mg} / \mathrm{dL}$, high-density lipoprotein $48 \mathrm{mg} / \mathrm{dL}$, systolic BP $120 \mathrm{mmHg}$, diabetes rate $5.5 \%$, and smoking rate $67 \%$. To the extent that a specific patient population differs from these characteristics, the model results may change. However, these patient characteristics primarily impact the cardiometabolic risks in the model, which have a minimal impact on the overall costs.

In addition, the model is based on the results of various comparative clinical trials, including CATIE, ${ }^{4}$ Study $234,{ }^{24}$ and a 12-month, open-label study comparing aripiprazole and olanzapine. ${ }^{25}$ In order to include lurasidone and aripiprazole in the model, these drugs were compared indirectly with the other model comparators from CATIE. Generally, naturalistic studies such as CATIE will show reduced effectiveness compared with clinical trials, which are designed to assess efficacy. However, the effect of this is mitigated to 
some extent by conducting an indirect treatment comparison, which involves a relative, not an absolute, comparison across treatments. While health care decision-makers increasingly recognize indirect treatment comparisons as an acceptable alternative method of comparison in the absence of realworld parallel-group data, differences in study populations may limit their comparability. CATIE was intended to be a real-world effectiveness trial; therefore, the study population represented a heterogeneous population of patients with chronic schizophrenia and comorbid conditions. Study 234 of lurasidone included patients who were previously treated with lurasidone or placebo for 6 weeks. ${ }^{24}$ The aripiprazole-olanzapine study included patients with either acute relapsing or chronic, stable schizophrenia. ${ }^{25}$ However, with the exception of the aripiprazole-olanzapine study, all of these studies involve patients with chronic, potentially stable schizophrenia. While there were some differences in the three different data sources, all these studies included patients who were already on active treatment with antipsychotics when they initiated the study treatment of choice and thus are likely to represent a relatively stable treated population.

This analysis used relapse-related hospitalizations avoided as the outcome measure, as opposed to QALYs, for two reasons. First, the model was developed from a US payer perspective, and it is generally understood that US payers are not interested in QALYs. Second, since none of the studies used to obtain effectiveness data included QALYs as an outcome measure, it was felt that incorporating QALYs would involve additional assumptions about the relationship between patient health states (relapse/no relapse) and QALYS and would not necessarily result in a significant relative difference in the outcomes.

Resource costs were estimated based on published literature and drug costs in the model were estimated based on mean drug utilization and published Red Book costs as of October 9, 2012. Changes in costs since this time may impact model results. The authors have sought to address modest variation in resource and drug costs within the sensitivity analyses; however, to the extent that these costs vary significantly, the model results may be impacted.

Treatment switching is common among patients with schizophrenia and was incorporated into this Markov cohort analysis through the use of a composite health state, consisting of average discontinuation rates, costs, and outcomes of noncomparator agents. This was done to ensure a consistent, simplified approach to account for several drug switches for tolerability/adverse event reasons across all model comparators. However, it is possible that treatment-switching patterns may potentially differ in the real world, resulting in different costs and outcomes.

Lastly, cardiometabolic risks were assumed to depend on patient characteristics and weight and lipid changes caused by the AAP agents. Weight and lipid changes were assumed to occur in a linear manner based on the amount of time on therapy. These changes were modeled at the cohort level for the average patient. Outcomes and cardiovascular risks for individual patients may vary. As this analysis incorporates only the known risk factors, it may underestimate the cardiovascular risks and costs associated with AAPs.

\section{Conclusion}

The cost-effectiveness of lurasidone compares favorably with generic AAPs (risperidone, ziprasidone, and olanzapine) and branded AAPs (quetiapine extended-release and aripiprazole). This may be driven by the clinical benefits of lurasidone, including efficacy in preventing hospitalizations and relapses in patients with schizophrenia, and its minimal cardiometabolic adverse event profile. Notwithstanding some of the limitations of the model, the results of this economic analysis indicate that, depending upon the decision-maker's willingness-to-pay threshold, lurasidone may be a cost-effective treatment option for patients with schizophrenia over a 5-year period. Given the implications of this model, further investigation through prospective comparative effectiveness studies or claims database analyses is warranted to confirm the cost-effectiveness of lurasidone in real-world settings.

\section{Disclosure}

This study was supported by funding from Sunovion Pharmaceuticals Inc. KR, AP, and AL are employees of Sunovion Pharmaceuticals Inc. KOD and KM are employees of Xcenda, a consulting company that provides services to several pharmaceutical companies, including Sunovion Pharmaceuticals Inc.

\section{References}

1. Wu EQ, Shi L, Birnbaum H, Hudson T, Kessler R. Annual prevalence of diagnosed schizophrenia in the USA: a claims data analysis approach. Psychol Med. 2006;36(11):1535-1540.

2. Wu EQ, Birnbaum HG, Shi L, et al. The economic burden of schizophrenia in the United States in 2002. J Clin Psychiatry. 2005;66(9): 1122-1129.

3. Ascher-Svanum H, Zhu B, Faries DE, Furiak NM, Montgomery W. Medication adherence levels and differential use of mental-health services in the treatment of schizophrenia. BMC Res Notes. 2009;2:6.

4. Lieberman JA, Stroup TS, McEvoy JP, et al; Clinical Antipsychotic Trials of Intervention. Effectiveness of antipsychotic drugs in patients with chronic schizophrenia. N Engl J Med. 2005;353:1209-1223. 
5. dosReis S, Johnson E, Steinwachs D, et al. Antipsychotic treatment patterns and hospitalizations among adults with schizophrenia. Schizophr Res. 2008;101(1-3):304-311.

6. Ahn J, McCombs JS, Jung C, et al. Classifying patients by antipsychotic adherence patterns using latent class analysis: characteristics of nonadherent groups in the California Medicaid (Medi-Cal) program. Value Health. 2008;11(1):48-56.

7. Agency for Healthcare Research and Quality. HCUP facts and figures: statistics on hospital-based care in the United States, 2008. Rockville, MD: Agency for Healthcare Research and Quality; 2010. Available from: http://www.hcup-us.ahrq.gov/reports.jsp. Accessed July 6, 2013.

8. Almond S, Knapp M, Francois C, Toumi M, Brugha T. Relapse in schizophrenia: costs, clinical outcomes and quality of life. $\mathrm{Br} J$ Psychiatry. 2004;184:346-351.

9. American Diabetes Association, American Psychiatric Association, American Association of Clinical Endocrinologists, North American Association for the Study of Obesity. Consensus development conference on antipsychotic drugs and obesity and diabetes. Diabetes Care. 2004;27(2):596-601.

10. McEvoy JP, Meyer JM, Goff DC, et al. Prevalence of the metabolic syndrome in patients with schizophrenia: baseline results from the Clinical Antipsychotic Trials of Intervention Effectiveness (CATIE) schizophrenia trial and comparison with national estimates from NHANES III. Schizophr Res. 2005;80(1):19-32.

11. Bresee LC, Majumdar SR, Patten SB, Johnson JA. Prevalence of cardiovascular risk factors and disease in people with schizophrenia: a population-based study. Schizophr Res. 2010;117(1):75-82.

12. Mathews M, Muzina DJ. Atypical antipsychotics: new drugs, new challenges. Cleve Clin J Med. 2007;74(8):597-606.

13. Sernyak MJ, Leslie DL, Alarcon RD, Losonczy MF, Rosenheck R Association of diabetes mellitus with use of atypical neuroleptics in the treatment of schizophrenia. Am J Psychiatry. 2002;159(4):561-566.

14. Weiden PJ, Mackell JA, McDonnell DD. Obesity as a risk factor for antipsychotic noncompliance. Schizophr Res. 2004;66(1):51-57.

15. Liu-Seifert H, Adams DH, Kinon BJ. Discontinuation of treatment of schizophrenic patients is driven by poor symptom response: a pooled post-hoc analysis of four atypical antipsychotic drugs. BMC Med. 2005;3:21.

16. Velligan DI, Lam YW, Glahn DC, et al. Defining and assessing adherence to oral antipsychotics: a review of the literature. Schizophr Bull. 2006;32(4):724-742.

17. Citrome L. Lurasidone for schizophrenia: a review of the efficacy and safety profile for this newly approved second-generation antipsychotic. Int J Clin Pract. 2011;65(2):189-210.

18. Rajagopalan K, O’Day K, Meyer K, et al. Time-on-therapy for atypical antipsychotics in a Markov cohort analysis. Abstract PMH86 presented at the International Society for Pharmacoeconomics and Outcomes Research Annual International Meeting, June 2-6, 2012, Washington, DC.

19. Bureau of Labor Statistics. Consumer Price Index, All Urban Consumers. Available from: http://data.bls.gov/cgi-bin/surveymost?cu. Accessed July 6, 2013.

20. Mullins CD. Double counting and the reporting of cost per event avoided. Clin Ther. 2006;28(4):602-603.

21. Nasrallah HA, Silva R, Phillips D, et al. Lurasidone for the treatment of acutely psychotic patients with schizophrenia: a 6-week, randomized, placebo-controlled study. J Psychiatr Res. 2013;47(5):670-677.

22. Meltzer HY, Cucchiaro J, Silva R, et al. Lurasidone in the treatment of schizophrenia: a randomized, double-blind, placebo- and olanzapinecontrolled study. Am J Psychiatry. 2011;168(9):957-967.

23. D'Agostino RB, Sr, Vasan RS, Pencina MJ, et al. General cardiovascular risk profile for use in primary care: the Framingham Heart Study. Circulation. 2008;117(6):743-753.

24. Loebel A, Cucchiaro J, Xu J, Sarma K, Pikalov A, Kane JM. Effectiveness of lurasidone vs quetiapine XR for relapse prevention in schizophrenia: a 12-month, double-blind, noninferiority study. Schizophr Res. 2013;147(1):95-102.
25. Chrzanowski WK, Marcus RN, Torbeyns A, Nyilas M, McQuade RD Effectiveness of long-term aripiprazole therapy in patients with acutely relapsing or chronic, stable schizophrenia: a 52-week, open-label comparison with olanzapine. Psychopharmacology. 2006;189(2): 259-266.

26. Kahn RS, Schulz SC, Palazov VD, et al; Study 132 Investigators. Efficacy and tolerability of once-daily extended release quetiapine fumarate in acute schizophrenia: a randomized, double-blind, placebocontrolled study. J Clin Psychiatry. 2007;68(6):832-842.

27. McEvoy JP, Lieberman JA, Stroup TS, et al; CATIE Investigators. Effectiveness of clozapine versus olanzapine, quetiapine, and risperidone in patients with chronic schizophrenia who did not respond to prior atypical antipsychotic treatment. Am J Psychiatry. 2006;163(4): 600-610.

28. McDermott S, Moran R, Platt T, Isaac T, Wood H, Dasari S. Heart disease, schizophrenia, and affective psychoses: epidemiology of risk in primary care. Community Ment Health J. 2005;41(6): 747-755.

29. Leslie DL, Rosenheck RA. Incidence of newly diagnosed diabetes attributable to atypical antipsychotic medications. Am J Psychiatry. 2004;161(9):1709-1711.

30. Arias E. United States life tables, 2007. National vital statistics reports. Hyattsville, MD: National Center for Health Statistics; 2011. Available from: http://www.cdc.gov/nchs/data/nvsr/nvsr59/nvsr59_09.pdf. Accessed July 6, 2013.

31. Hor K, Taylor M. Review: suicide and schizophrenia: a systematic review of rates and risk factors. J Psychopharmacol. 2010;24(Suppl 4):81-90.

32. O'Sullivan AK, Rubin J, Nyambose J, Kuznik A, Cohen DJ, Thompson D. Cost estimation of cardiovascular disease events in the US. Pharmacoeconomics. 2011;29(8):693-704.

33. RedBook Online. Micromedex 2.0, Thomson Reuters. Accessed October 9, 2012

34. Ascher-Svanum H, Zhu B, Faries DE, et al. The cost of relapse and the predictors of relapse in the treatment of schizophrenia. $B M C$ Psychiatry. 2010;10:2. Available from: http://www.micromedexsolutions.com/home/dispatch.

35. American Diabetes Association. Economic costs of diabetes in the US in 2007. Diabetes Care. 2008;31(3):596-615.

36. Rajagopalan K, Hassan M, O’Day K, Meyer K, Grossman F. Costeffectiveness of lurasidone vs aripiprazole among patients with schizophrenia who have previously failed on an atypical antipsychotic: an indirect comparison of outcomes from clinical trial data. J Med Econ. 2013;16(7):951-961.

37. Furiak NM, Ascher-Svanum H, Klein RW, et al. Cost-effectiveness model comparing olanzapine and other oral atypical antipsychotics in the treatment of schizophrenia in the United States. Cost Eff Resour Alloc. 2009; 7:4

38. McIntyre RS, Cragin L, Sorensen S, Naci H, Baker T, Roussy JP. Comparison of the metabolic and economic consequences of long-term treatment of schizophrenia using ziprasidone, olanzapine, quetiapine and risperidone in Canada: a cost-effectiveness analysis. J Eval Clin Pract. 2010;16(4):744-755.

39. Ascher-Svanum H, Stensland MD, Peng X, et al. Cost-effectiveness of olanzapine vs aripiprazole in the treatment of schizophrenia. Curr Med Res Opin. 2011;27(1):115-122.

40. Cooper D, Moisan J, Abdous B, Grégoire JP. A population-based cost-effectiveness analysis of olanzapine and risperidone among ambulatory patients with schizophrenia. Can J Clin Pharmacol. 2008;15(3):e385-e397.

41. Lehman AF, Lieberman JA, Dixon LB, et al; American Psychiatric Association; Steering Committee on Practice Guidelines. Practice guideline for the treatment of patients with schizophrenia, second edition. Am J Psychiatry. 2004;161(Suppl 2):1-56.

42. Kreyenbuhl J, Buchanan RW, Dickerson FB, Dixon LB; Schizophrenia Patient Outcomes Research Team (PORT). The schizophrenia Patient Outcomes Research Team (PORT): updated treatment recommendations 2009. Schizophr Bull. 2010;36(1):94-103. 
43. Naber D, Lambert M. The CATIE and CUtLASS studies in schizophrenia: results and implications for clinicians. CNS Drugs. 2009;23(8):649-659.

44. Buchanan RW, Kreyenbuhl J, Kelly DL, et al; Schizophrenia Patient Outcomes Research Team (PORT). The 2009 schizophrenia PORT psychopharmacological treatment recommendations and summary statements. Schizophr Bull. 2010;36(1):71-93.

45. Jones PB, Barnes TR, Davies L, et al. Randomized controlled trial of the effect on quality of life of second- vs first-generation antipsychotic drugs in schizophrenia: Cost Utility of the Latest Antipsychotic Drugs in Schizophrenia Study (CUtLASS 1). Arch Gen Psychiatry. 2006;63(10):1079-1087.
46. Llorente MD, Urrutia V. Diabetes, psychiatric disorders, and the metabolic effects of antipsychotic medications. Clin Diabetes. 2006; 24(1):18-24.

47. Patel KH, Hlavinka PF. Schizophrenia: optimal therapy with secondgeneration antipsychotic agents. Pharmacy Today. 2007;13(11): 71-84.

48. Citrome L, Nasrallah HA. On-label on the table: what the package insert informs us about the tolerability profile of oral atypical antipsychotics, and what it does not. Expert Opin Pharmacother. 2012; 13(11):1599-1613.

49. Latuda (lurasidone $\mathrm{HCl}$ ) [package insert]. Marlborough, MA: Sunovion Pharmaceuticals Inc; 2010.

\section{Publish your work in this journal}

ClinicoEconomics \& Outcomes Research is an international, peerreviewed open-access journal focusing on Health Technology Assessment, Pharmacoeconomics and Outcomes Research in the areas of diagnosis, medical devices, and clinical, surgical and pharmacological intervention. The economic impact of health policy and health systems organization also constitute important areas of coverage. The manuscript management system is completely online and includes a very quick and fair peer-review system, which is all easy to use. Visit http://www.dovepress.com/testimonials.php to read real quotes from published authors.

Submit your manuscript here: http://www.dovepress.com/clinicoeconomics-and-outcomes-research-journal 